\title{
Emergence of serotype K1 Klebsiella pneumoniae ST23 strains co-producing the plasmid-mediated AmpC beta-lactamase DHA-1 and an extended-spectrum beta- lactamase in Korea
}

Hae Suk Cheong ${ }^{1}$, Doo Ryeon Chung ${ }^{2,3^{*}}$, Chaeyoeng Lee ${ }^{3}$, So Hyun Kim ${ }^{3}$, Cheol-In Kang ${ }^{2}$, Kyong Ran Peck ${ }^{2}$ and Jae-Hoon Song ${ }^{2,3}$

\begin{abstract}
Background: Serotype K1 Klebsiella pneumoniae has emerged as an important community pathogen causing various infections, including liver abscesses. Although serotype K1 K. pneumoniae community isolates have been reported as susceptible to most classes of antimicrobial agents, a few cases of infection caused by extended-spectrum beta-lactamase (ESBL)-producing serotype K1 K. pneumoniae have recently been reported in Asian countries. We identified three ESBL-producing strains of serotype K1 K. pneumoniae and conducted a molecular characterization of their drug resistance.

Methods: Three ESBL-producing serotype K1 K. pneumoniae ST23 strains were identified from strains in the Asian Bacterial Bank. Antimicrobial susceptibility testing was performed using the broth microdilution method, and ESBL production was tested by the double-disk synergy test and a confirmatory test. PCR was performed to detect the genes for plasmid-mediated ESBL and AmpC beta-lactamases.

Results: All three strains were resistant to cefotaxime, ceftazidime, and piperacillin/tazobactam, and all were determined to be ESBL-producers. No known ESBL genes, including bla $a_{\mathrm{SHV}}$, bla $a_{\mathrm{TEM}}$, bla $a_{\mathrm{CTX}-\mathrm{M}}$, bla $a_{\mathrm{GES}}$, bla $a_{\mathrm{PER}}$, and $b_{a_{V E B}}$ were detected among the three strains. Of all plasmid-mediated AmpC beta-lactamase (PAB) genes, including bla $a_{\mathrm{DHA}-1}, b a_{\mathrm{CMY}}, b / a_{\mathrm{FOX}}$, and bla $a_{\mathrm{MOX}}$, the bla $a_{\mathrm{DHA}-1}$ gene was detected in two of the strains. The PFGE patterns revealed that the two isolates carrying bla $a_{\mathrm{DHA}-1}$ were closely related (84\% similarity).
\end{abstract}

Conclusions: No ESBL genes were detected among three ESBL-producing serotype K1 K. pneumoniae ST23 strains. Two strains contained the PAB gene bla $a_{\mathrm{DHA}-1}$. The emergence of resistant strains of community-origin serotype $\mathrm{K} 1 \mathrm{~K}$. pneumoniae has important implications for effective treatment and infection control practices.

Keywords: Klebsiella pneumoniae, Extended-spectrum beta-lactamase, AmpC beta-lactamase

\footnotetext{
* Correspondence: iddrchung@gmail.com

2Division of Infectious Diseases, Department of Internal Medicine, Samsung

Medical Center, Sungkyunkwan University School of Medicine, 81 Irwon-Ro,

Gangnam-gu, Seoul 06351, Republic of Korea

${ }^{3}$ Asia Pacific Foundation for Infectious Diseases (APFID), Seoul, Korea

Full list of author information is available at the end of the article
} 


\section{Background}

The rates of extended-spectrum beta-lactamase (ESBL)production in Klebsiella pneumoniae are very high in hospitals worldwide, and highly resistant strains such as K. pneumoniae carbapenemase (KPC) or New Delhi metallo-beta-lactamase (NDM)-producing $K$. pneumoniae have been rapidly spreading between countries. Treatment of infections caused by multidrug-resistant $K$. pneumoniae has been a challenge, and there is increasing concern about the economic impact of these bacteria.

Serotype K1 K. pneumoniae has been reported as the predominant serotype among those isolates causing liver abscesses [1, 2]. Most K1 strains isolated from liver abscess cases belong to sequence type (ST) 23 in Asian countries [3, 4]. Although ESBL K. pneumoniae and KPC-producing $K$. pneumoniae have become globally widespread, a distinctive characteristic of $\mathrm{K} 1$ K. pneumoniae ST23 has been good susceptibility to most antibiotic classes (except ampicillin and piperacillin) [5], however, ESBL-producing K1 K. pneumoniae strains have begun to be reported recently [6, 7]. In this study, we report serotype $\mathrm{K} 1 \mathrm{~K}$. pneumoniae strains co-producing the plasmid-mediated AmpC beta-lactamase (PAB) DHA-1 and ESBL.

\section{Materials and methods}

Three ESBL-producing serotype K1 K. pneumoniae ST23 strains were identified from strains in the Asian Bacterial Bank (Asia Pacific Foundation for Infectious Diseases, Seoul, Korea), which had been collected during bacteremia studies in Korea between 2006 and 2008.

In vitro antimicrobial susceptibility testing was performed using the broth microdilution method according to the Clinical and Laboratory Standards Institute (CLSI) guidelines [8]. Ten antimicrobial agents were tested, including ampicillin (AMP), amikacin (AMI), ceftazidime (CAZ), tetracycline (TET), cefepime (CPM), cefotaxime (CTX), ciprofloxacin (CIP), rifampicin (RIF), and piperacillin/ tazobactam $(\mathrm{P} / \mathrm{T})$. For ESBL-positive candidates, which presented a ceftazidime or cefotaxime minimum inhibitory concentration $(\mathrm{MIC}) \geq 2 \mathrm{mg} / \mathrm{L}$, production of ESBL was confirmed by the double-disk synergy test using $\mathrm{BBL}^{\text {тм }}$ Sensi-Disc $^{\mathrm{Tm}}$ kits (Becton Dickinson, Franklin Lakes, NJ, USA) according to CLSI guidelines [8]. Quality control for
ESBL production was performed using E. coli ATCC 25922 and K. pneumoniae ATCC 700603.

Double-disk synergy test-positive isolates were further tested by polymerase chain reaction (PCR) and sequence analyses to determine the gene responsible for the ESBL phenotype in the ESBL producers. In the ESBL-producing K. pneumoniae isolates, bla $a_{\mathrm{TEM}}, b l a_{\mathrm{SHV}}, b l a_{\mathrm{CTX}-\mathrm{M}}, b l a_{\mathrm{GES}}$, $b l a_{\mathrm{PER}}$, and $b l a_{\mathrm{VEB}}$ genes were tested by PCR. In addition, $b l a_{\mathrm{DHA}-1}, b l a_{\mathrm{CMY}}, b l a_{\mathrm{FOX}}, b l a_{\mathrm{MOX}}, b l a_{\mathrm{IMP}}, b l a_{\mathrm{VIM}}, b l a_{\mathrm{OXA}}$, and $b l a_{\mathrm{NDM}}$ genes were tested. The sequences were compared with those in the GenBank nucleotide database for subtyping.

To determine serotype K1, PCR was conducted using a primer pair specific for $m a g \mathrm{~A}$, which is a gene specific for the $\mathrm{K} 1$ antigen. The primers were chosen as previously described: forward, 5'GGTGCTCTTTACATCATTGC-3', and reverse, 5'-GCAATGGCCATTTGCGT TAG-3' [9]. Multilocus sequence typing (MLST) was conducted using the nucleotide sequences of seven housekeeping genes (gagA, infB, $m d h, p g i, p h o E, r p o B$, and ton $B$ ) as previously described [10]. For pulsed field gel electrophoresis (PFGE), agarose-embedded bacterial genomic DNA was digested with $20 \mathrm{U}$ of $\mathrm{XbaI}$. The restriction fragments were separated by gel electrophoresis in $0.5 \times$ Tris-borate-EDTA buffer. Electrophoresis was performed using a CHEF Mapper XA (Bio-Rad Laboratories, Hercules, CA, USA). The PFGE patterns were analyzed using GelCompar II version 6.1 (Applied Maths, Belgium).

\section{Results}

Of the $120 \mathrm{~K}$. pneumoniae isolates, 20 (16.7\%) were ESBLproducers. Among the ESBL-producers, only three were determined to be serotype K1 (KPN1, KPN2, and KPN3). Antimicrobial susceptibilities of the three isolates are shown in Table 1. All three strains were resistant to ampicillin, piperacillin-tazobactam, cefotaxime, ceftazidime, and rifampin. Two strains (KPN2 and KPN3) were also resistant to amikacin and ciprofloxacin. One strain (KPN2) was resistant to imipenem. In all three strains, no ESBL genes, including bla $a_{\mathrm{TEM}}, b l a_{\mathrm{SHV}}, b l a_{\mathrm{CTX}-\mathrm{M}}, b l a_{\mathrm{GES}}, b l a_{\mathrm{PER}}$, and $b l a_{\mathrm{VEB}}$, were detected. Among the PAB genes (bla $a_{\mathrm{DHA}-1}$, $b l a_{\mathrm{CMY}}, b l a_{\mathrm{FOX}}$, and $\left.b l a_{\mathrm{MOX}}\right)$, only $b l a_{\mathrm{DHA}-1}$ was detected in two strains (KPN2 and KPN3). Carbapenemase genes were also not detected in all three isolates (Table 2). Clonal relatedness was investigated by PFGE for the two strains.

Table 1 Antimicrobial susceptibilities in K1 K. pneumoniae ST23 strains

\begin{tabular}{|c|c|c|c|c|c|c|c|c|c|c|c|c|c|c|c|c|c|c|c|c|}
\hline \multirow{3}{*}{$\begin{array}{l}\text { Strain } \\
\text { KPN1 }\end{array}$} & \multicolumn{20}{|c|}{ MICs and antimicrobial susceptibility } \\
\hline & \multicolumn{2}{|c|}{ AMP } & \multicolumn{2}{|l|}{$\mathrm{P} / \mathrm{T}$} & \multicolumn{2}{|c|}{ CTX } & \multicolumn{2}{|l|}{ CAZ } & \multicolumn{2}{|c|}{ CPM } & \multicolumn{2}{|l|}{ CIP } & \multicolumn{2}{|l|}{ AMI } & \multicolumn{2}{|c|}{ TET } & \multicolumn{2}{|l|}{$\mathrm{IMI}$} & \multicolumn{2}{|l|}{ RIF } \\
\hline & $>64$ & $\mathrm{R}$ & $>256$ & $\mathrm{R}$ & 16 & $\mathrm{R}$ & $>64$ & $\mathrm{R}$ & $>64$ & $\mathrm{R}$ & 0.125 & $S$ & 4 & S & 1 & S & 0.5 & S & 64 & $\mathrm{R}$ \\
\hline KPN2 & $>64$ & $\mathrm{R}$ & $>256$ & $\mathrm{R}$ & 32 & $\mathrm{R}$ & $>64$ & $\mathrm{R}$ & 32 & $\mathrm{R}$ & 4 & $\mathrm{R}$ & $>128$ & $\mathrm{R}$ & 4 & S & 4 & $\mathrm{R}$ & 64 & $\mathrm{R}$ \\
\hline KPN3 & $>64$ & R & $>256$ & $R$ & 32 & R & $>64$ & R & 0.5 & $S$ & 2 & 1 & $>128$ & $R$ & 2 & $S$ & 0.125 & $S$ & 64 & R \\
\hline
\end{tabular}

MIC minimum inhibitory concentration, $R$ resistant, $/$ intermediate, $S$ susceptible, $A M P$ ampicillin, $P / T$ piperacillin/tazobactam, $C T X$ cefotaxime, $C A Z$ ceftazidime, $C P M$ cefepime, CIP ciprofloxacin, AMI amikacin, TET tetracycline, IMI imipenem, RIF rifampin 
Table 2 Detection of ESBL genes and plasmid-mediated AmpC $\beta$-lactamase genes in K1 K. pneumoniae ST23 strains

\begin{tabular}{|c|c|c|c|c|c|c|c|c|c|c|c|c|c|c|c|c|c|c|c|c|}
\hline \multirow[t]{2}{*}{ Strain } & \multicolumn{10}{|c|}{ ESBL genes } & \multicolumn{6}{|c|}{ Plasmid-mediated AmpC $\beta$-lactamase genes } & \multicolumn{4}{|c|}{ Others } \\
\hline & TEM & $\mathrm{SHV}$ & CTX-M & PER & KPC & PER & VEB & $\mathrm{GES} / \mathrm{IBC}$ & SME & $\mathrm{IMI} / \mathrm{NMC}$ & $\overline{C M Y}$ & $\mathrm{ACT}$ & FOX & $\mathrm{DHA}$ & ACC & MOX & $\overline{I M P}$ & VIM & OXA & $\overline{N D M}$ \\
\hline KPN1 & - & $-{ }^{b}$ & - & - & - & - & - & - & - & - & - & - & - & - & - & - & - & - & - & - \\
\hline KPN2 & $-{ }^{a}$ & $-\mathrm{b}$ & - & - & - & - & - & - & - & - & - & - & - & DHA-1 & - & - & - & - & - & - \\
\hline KPN3 & - & $-b$ & - & - & - & - & - & - & - & - & - & - & - & DHA-1 & - & - & - & - & - & - \\
\hline
\end{tabular}

${ }^{\mathrm{a}} \mathrm{TEM}-1$ (not an ESBL gene), ${ }^{\mathrm{b}} \mathrm{SHV}-11$ (not an ESBL gene)

Analysis of the PFGE patterns showed that the two isolates carrying $b l a_{\text {DHA-1 }}$ were closely related ( $84 \%$ similarity).

\section{Discussion}

Serotype K1 K. pneumoniae ST23 is, a highly virulent pathogenic strain causing invasive community-acquired infections, that is widespread in its geographical distribution in Asia [5]. Fortunately, ST23 strains have shown good susceptibility to most antibiotics. However, the advent of multidrug resistance with high transmission potential in $K$. pneumoniae serotype $\mathrm{K} 1$ causes serious concerns. A few strains of ESBL-producing serotype K1 K. pneumoniae have already been reported in Asian countries $[6,7,11]$. In the present study, we report serotype K1 K. pneumoniae strains co-producing the PAB DHA-1 and ESBL. We found three isolates that were phenotypically ESBL producers, but we could not detect any bla genes responsible for the ESBL phenotype. Therefore, other ESBL genotypes may be involved. In addition, two of the three isolates were identified as PAB. Recently, gram-negative organisms that produce both ESBLs and PAB enzymes have increasingly been described worldwide [12-15]. To our knowledge, this is the first report of serotype $\mathrm{K} 1 \mathrm{~K}$. pneumoniae producing both ESBL and PAB. Both ESBLs and $\mathrm{PAB}$ enzymes are associated with broad, multidrug resistance because multiple antibiotic-resistance genes exist on the same plasmid [16]. One isolate (KPN3) in our study showed carbapenem resistance in the broth microdilution test. Subsequently, we used PCR analysis to determine the presence of carbapenemase genes, such as $b l a_{\mathrm{IMP}} b l a_{\mathrm{VIM}}$, $b l a_{\mathrm{OXA}}$, and $b l a_{\mathrm{NDM}}$; however, none of these genes were detected. The frequency of $\mathrm{PAB}$ transmission may be higher than initially thought, especially if the spread of resistance mimics the trend that we have seen occurring over the past few years for ESBLs. Moreover, porin alteration, combined with the production of ESBL or PAB, has been demonstrated to confer carbapenem resistance $[17,18]$. We also characterized antimicrobial susceptibility between non-serotype K1 and serotype K1 ESBL-producing K. pneumoniae. Although the number of total isolates was too small to draw definite conclusions, the resistant rates of piperacillin-tazobactam and imipenem in $\mathrm{K} 1$ isolates tended to be high. It is uncertain whether the increase of antimicrobial resistance in serotype $\mathrm{K} 1 \mathrm{~K}$. pneumoniae is connected with any one particular resistance gene.
The emergence of multidrug-resistant strains with high transmission potential in serotype $\mathrm{K} 1 \mathrm{~K}$. pneumoniae is of great concern due to limited alternative treatment options and the possibility of global dissemination. Careful surveillance of resistant strains and adequate infection prevention and control measures are necessary.

\section{Abbreviations}

ESBL: Extended-spectrum beta-lactamase; PAB: Plasmid-mediated AmpC beta-lactamase; PFGE: Pulsed-field gel electrophoresis; KPC: Klebsiella pneumoniae carbapenemase; NDM: New Delhi metallo-beta-lactamase; CLSI: Clinical and Laboratory Standards Institute; MIC: Minimum inhibitory concentration; PCR: Polymerase chain reaction

\section{Acknowledgements}

A portion of this work was presented at the annual meeting of the Korean Society of Infectious Diseases in Jeju, South Korea on Nov 01, 2012.

\section{Funding}

The Basic Science Research Program through the National Research Foundation of Korea (NRF), funded by the Ministry of Education, Science and Technology (2012R1A1A2006672), supported this research.

Availability of data and materials

All the data supporting conclusions are available in Tables 1 and 2.

\section{Authors' contributions}

HSC and DRC performed the data collection. CL carried out the microbiological analysis. SHK, CK, KRP, and JS conceived the study, participated in its design and drafted the manuscript. All authors read and approved the final manuscript.

\section{Competing interests}

The authors declare that they have no competing interests.

Consent for publication

Not applicable.

Ethics approval and consent to participate

We used organisms from the Asian Bacterial Bank that had been collected during bacteremia studies in Korea. The Samsung Medical Center Institutional Review Board (2007-05-064) approved this study.

\section{Author details}

'Division of Infectious Diseases, Department of Internal Medicine, Konkuk University Medical Center, Konkuk University School of Medicine, Seoul, Republic of Korea. ${ }^{2}$ Division of Infectious Diseases, Department of Internal Medicine, Samsung Medical Center, Sungkyunkwan University School of Medicine, 81 Irwon-Ro, Gangnam-gu, Seoul 06351, Republic of Korea. ${ }^{3}$ Asia Pacific Foundation for Infectious Diseases (APFID), Seoul, Korea.

Received: 3 September 2016 Accepted: 22 November 2016 Published online: 28 November 2016

\section{References}

1. Fang CT, Lai SY, Yi WC, Hsueh PR, Liu KL, Chang SC. Klebsiella pneumoniae genotype K1: an emerging pathogen that causes septic ocular or central nervous system complications from pyogenic liver abscess. Clin Infect Dis. 2007:45(3):284-93. 
2. Chung DR, Lee SS, Lee HR, et al. Emerging invasive liver abscess caused by K1 serotype klebsiella pneumoniae in korea. J Infect. 2007;54(6):578-83.

3. Liu YM, Li BB, Zhang YY, et al. Clinical and molecular characteristics of emerging hypervirulent klebsiella pneumoniae bloodstream infections in mainland china. Antimicrob Agents Chemother. 2014;58(9):5379-85.

4. Chung DR, Lee HR, Lee SS, et al. Evidence for clonal dissemination of the serotype K1 klebsiella pneumoniae strain causing invasive liver abscesses in korea. J Clin Microbiol. 2008;46(12):4061-3.

5. Chung DR, Park MH, Kim SH, et al. Prevalence and molecular characterization of serotype $\mathrm{K} 1$ klebsiella pneumoniae strains from various clinical specimen sources in 11 asian countries. J Infect. 2012;64(6):622-5.

6. Su SC, Siu LK, Ma L, et al. Community-acquired liver abscess caused by serotype K1 klebsiella pneumoniae with CTX-M-15-type extended-spectrum beta-lactamase. Antimicrob Agents Chemother. 2008;52(2):804-5.

7. Nagano N, Cordevant C, Nagano Y. Upper and lower urinary tract infection caused by klebsiella pneumoniae serotype K2 and CTX-M-15 betalactamase-producing serotype $\mathrm{K} 1$ : a case report and characterization of serum killing resistance. J Med Microbiol. 2008;57(Pt 1):121-4.

8. Clinical and Laboratory Standards Institute(CLSI). Performance standards for antimicrobial susceptibility testing, 20th informational supplement M100S22. Wayne: CLSI; 2010.

9. Struve C, Bojer M, Nielsen EM, Hansen DS, Krogfelt KA. Investigation of the putative virulence gene magA in a worldwide collection of 495 klebsiella isolates: magA is restricted to the gene cluster of klebsiella pneumoniae capsule serotype K1. J Med Microbiol. 2005;54(Pt 11):1111-3.

10. Diancourt L, Passet V, Verhoef J, Grimont PA, Brisse S. Multilocus sequence typing of klebsiella pneumoniae nosocomial isolates. J Clin Microbiol. 2005;43(8):4178-82.

11. Qi Y, Wei Z, Li L, et al. Detection of a common plasmid carrying blaKPC-2 in enterobacteriaceae isolates from distinct cities in china. Microb Drug Resist. 2010;16(4):297-301.

12. Cheong HS, Ko KS, Kang Cl, Chung DR, Peck KR, Song JH. Clinical significance of infections caused by extended-spectrum beta-lactamaseproducing enterobacteriaceae blood isolates with inducible AmpC betalactamase. Microb Drug Resist. 2012;18(4):446-52.

13. Cheong HS, Ko KS, Kang Cl, Chung DR, Peck KR, Song JH. Clinical significance of infections caused by plasmid-mediated AmpC betalactamases and extended-spectrum beta-lactamase-producing escherichia coli. Infection. 2013;41(1):287-91.

14. Denisuik AJ, Lagace-Wiens PR, Pitout JD, et al. Molecular epidemiology of extended-spectrum beta-lactamase-, AmpC beta-lactamase- and carbapenemase-producing escherichia coli and klebsiella pneumoniae isolated from canadian hospitals over a 5 year period: CANWARD 2007-11. J Antimicrob Chemother. 2013;68 Suppl 1:i57-65.

15. Lee CH, Su LH, Li CC, Chien CC, Tang YF, Liu JW. Microbiologic and clinical implications of bacteremia due to extended-spectrum-beta-lactamaseproducing klebsiella pneumoniae with or without plasmid-mediated AmpC beta-lactamase DHA-1. Antimicrob Agents Chemother. 2010:54(12):5395-8.

16. Yoon YK, Cheong HW, Pai $\mathrm{H}$, et al. Molecular analysis of a prolonged spread of klebsiella pneumoniae co-producing DHA-1 and SHV-12 beta-lactamases. J Microbiol. 2011:49(3):363-8.

17. Reuland EA, Halaby T, Hays JP, et al. Plasmid-mediated AmpC: prevalence in community-acquired isolates in Amsterdam, the Netherlands, and risk factors for carriage. PLoS One. 2015;10(1):e0113033.

18. Matsumura Y, Tanaka M, Yamamoto M, et al. High prevalence of carbapenem resistance among plasmid-mediated AmpC beta-lactamaseproducing klebsiella pneumoniae during outbreaks in liver transplantation units. Int J Antimicrob Agents. 2015;45(1):33-40.

\section{Submit your next manuscript to BioMed Central and we will help you at every step:}

- We accept pre-submission inquiries

- Our selector tool helps you to find the most relevant journal

- We provide round the clock customer support

- Convenient online submission

- Thorough peer review

- Inclusion in PubMed and all major indexing services

- Maximum visibility for your research

Submit your manuscript at www.biomedcentral.com/submit

) Biomed Central 